\title{
The Association between Excessive Internet Gaming Behavior and Immersive Tendency, Mediated by Attention Deficit/Hyperactivity Disorder Symptoms, in Korean Male University Students
}

\author{
Dooyoung Jung1, Eun-jung Shim², Hyeonggyu Park ${ }^{3}$ Kwanglo Lee', Sangil Lee', Eun-young Kim ${ }^{4,5}$, \\ Jae Seung Chang ${ }^{6}$, Seong-hoon Jeong ${ }^{7}$, Yeni Kim ${ }^{8,9}$, Yong Min Ahn ${ }^{10,11}$, and Bong-jin Hahm ${ }^{10,11} \bowtie$ \\ ${ }^{1}$ Department of Human Factors Engineering, Ulsan National Institute of Science and Technology, Ulsan, Republic of Korea \\ ${ }^{2}$ Department of Psychology, Pusan National University, Busan, Republic of Korea \\ ${ }^{3}$ Korea Transportation Safety Authority, Gimcheon, Republic of Korea \\ ${ }^{4}$ Mental Health Center, Seoul National University Health Care Center, Seoul, Republic of Korea \\ ${ }^{5}$ Department of Medicine, Seoul National University College of Medicine, Seoul, Republic of Korea \\ ${ }^{6} \mathrm{JC}$ Research House, Seoul, Republic of Korea \\ ${ }^{7}$ Department of Psychiatry, Eulji University School of Medicine, Eulji University Hospital, Daejeon, Republic of Korea \\ ${ }^{8}$ National Center for Mental Health, Seoul, Republic of Korea \\ ${ }^{9}$ Department of Psychiatry, Dongguk University International Hospital, Institute of Clinical Psychopharmacology, Dongguk University School of Medicine, \\ Goyang, Republic of Korea \\ ${ }^{10}$ Department of Neuropsychiatry, Seoul National University Hospital, Seoul, Republic of Korea \\ ${ }^{11}$ Department of Psychiatry and Behavioral Sciences, Seoul National University College of Medicine, Seoul, Republic of Korea
}

Objective Problematic online gaming (POG) and problematic Internet use (PIU) have become a serious public mental health problem, with Internet gaming disorder (IGD) included in "Conditions for further study" section of DSM-5. Although higher immersive tendency is observed in people affected by POG, little is known about the simultaneous effect of immersive tendency and its highly comorbid mental disorder, attention deficit/hyperactivity disorder (ADHD). This study aimed to assess the relationship between immersive tendency, ADHD, and IGD.

Methods Cross-sectional interview study was conducted in Seoul, Korea with 51 male undergraduate students; 23 active gamers and 28 controls.

Results Current ADHD symptoms showed partial mediation effect on the path of immersive tendency on POG and PIU. The mediation model with inattention explained variance in both POG and PIU better than other current ADHD symptom models $\left(\mathrm{R}^{2}=69.2\right.$ in POG; 69.3 in PIU). Childhood ADHD symptoms models demonstrated mediation effect on both POG and PIU which explained less variance than current $\mathrm{ADHD}$ symptom models $\left(\mathrm{R}^{2}=53.7\right.$ in POG; 52.1 in PIU). Current ADHD symptoms, especially inattention, appear to mediate the effect of immersive tendency on POG/PIU.

Conclusion Immersive tendencies may entail greater susceptibility to IGD, and comorbidity with ADHD may mediate the effect of immersive tendency on IGD.

Psychiatry Investig 2020;17(5):403-411

Key Words Attention deficit/hyperactivity disorder, Immersive tendency, Internet gaming disorder, Problematic Internet use, Problematic online gaming.

\section{INTRODUCTION}

Although problematic online gaming (POG) and problematic Internet use (PIU) have become a significant public men- tal health problem, their definitions and diagnoses remain heterogeneous. In 2013, internet gaming disorder (IGD) was included in section three, "Conditions for further study," of the Diagnostic and Statistical Manual of Mental Disorders, Fifth

\footnotetext{
Received: July 9, 2019 Revised: January 22, 2020 Accepted: February 19, 2020

$\triangle$ Correspondence: Bong-jin Hahm, MD, PhD

Department of Psychiatry and Behavioral Sciences, Seoul National University College of Medicine, 101 Daehak-ro, Jongno-gu, Seoul 03080, Republic of Korea Tel: +82-2-2072-2557, Fax: +82-2-744-7241, E-mail: hahmbj@gmail.com

(c) This is an Open Access article distributed under the terms of the Creative Commons Attribution Non-Commercial License (https://creativecommons.org/licenses/by-nc/4.0) which permits unrestricted non-commercial use, distribution, and reproduction in any medium, provided the original work is properly cited.
} 
Edition (DSM-5). ${ }^{1}$ Of the non-substance addictive behaviors, only gambling disorder has been reclassified in the substancerelated and addictive disorders section. Although IGD shares common properties with substance use disorder and pathologic gambling, research on IGD is not yet sufficient to support the establishment of specific diagnostic criteria. ${ }^{2}$ To clarify this complicated concept, a study on IGD risk factors and comorbidities was recommended. ${ }^{3}$

There are several risk factors associated with POG and PIU. Older adolescents and young adult males were the most vulnerable groups associated with $\mathrm{POG}^{4}$ and male gender is also considered to have a higher susceptibility to PIU. ${ }^{5}$ In terms of cognitive function, intelligence and flexibility are associated with both POG and PIU. ${ }^{6,7}$ In an adolescent study, lower selfesteem and satisfaction with daily life were associated with POG severity, but only in males. ${ }^{8}$ In a hierarchical model that included gender, age, cognitive function, and social interaction, psychopathological conditions such as attention, mood, anxiety, and impulsivity were the strongest risk factors for POG. ${ }^{9}$ Among the psychopathological conditions associated with POG, attention deficit/hyperactivity disorder (ADHD) has been suggested to be the most significant predictor of POG by both cross-sectional and prospective studies. ${ }^{10}$ In a study of young adult college students, adult ADHD and depressive disorder were associated with PIU, but only in males. ${ }^{11}$ In a systematic review of PIU and comorbid psychopathology, depression and ADHD symptoms showed the most significant and consistent correlations with PIU. ${ }^{12}$ In a recent study of a representative sample of European adolescents, while PIU was associated with depression, POG was associated with male gender and peer problems. ${ }^{13}$

Online gaming user experiences are associated with POG. ${ }^{14}$ Witmer and Singer (1998) defined "presence" as the subjective experience of being in one place or environment, even when one is physically situated in another. The authors also developed a theoretical construct called "immersive tendency," which relates to the tendency to become involved in a continuous stream of stimuli. While presence is an experiential concept, immersive tendency is a personality trait positively correlated with presence. It is the disposition to become involved in everyday activities, and the ability to focus on a particular activity. Immersive tendency is evaluated according to everyday activities, such as watching movies, reading novels, and dreaming, while presence is evaluated according to individual experiences in mediated environments. In a recent study with high-ranked game players, addicted gamers had higher immersive tendency than highly engaged, non-addicted players. ${ }^{15}$ In concept, immersive tendency may be a specific risk factor for IGD independent of gaming context, such as a player's motivation.

To our knowledge, no study has examined the relationship between immersive tendency and POG/PIU with comorbid psychopathologies such as ADHD and depression. The aim of the study was to investigate whether the direct relationship between immersive tendency and POG/PIU is mediated by ADHD symptoms.

\section{METHODS}

This study was conducted with undergraduate students. To minimize the influence of confounding factors, we restricted our sample to a homogeneous population of male students, aged 19-29 years, from two high-ranking universities in South Korea (Seoul National University and Yonsei University). For another physiological experiment, we recruited 26 actively gaming and 29 control students. Several conditions were included as participant screening criteria: 1) a maladaptive preoccupation with both online and offline computer gaming; 2) severe suffering or impairment due to computer gaming; 3) a Young's Internet Addiction Test (YIAT) score of more than 50 points; ${ }^{16}$ and 4) more than four hours of computer gaming daily. ${ }^{17}$ A psychiatrist interviewed the participants to assess for any Axis I psychiatric disorders that could lead to excessive computer usage, such as mania, hypomania, or a substance-related disorder. The psychiatrist rated the severity of participants' depression using the Montgomery-Åsberg Depression Rating Scale, to exclude participants with significant depression. ${ }^{18}$ One participant was diagnosed with bipolar disorder and ADHD, and excluded on this basis. Another participant was excluded because he was receiving treatment for narcolepsy with stimulant medication. Two participants were excluded as they returned incomplete questionnaires. In total, the analysis was conducted with 51 male undergraduate students; 23 active gamers and 28 control participants. Written consents were obtained from participants before the experiment.

The Institutional Review Board of the Seoul National University Hospital approved the study protocol (IRB 1101-090-349), and we obtained written informed consent from each participant.

\section{Measures}

\section{Immersive tendency}

Immersive tendency was evaluated using an immersive tendency questionnaire. ${ }^{19}$ The questionnaire consists of 18 items, with a seven-point Likert scale and possible scores ranging from 0 to 108 . The scale measures a tendency toward immersion in everyday activities. It was expected that participants with high immersive tendency would experience presence in a mediated environment, such as, "Do you easily become deeply involved in movies or tv drama?" "Do you become so involved in a movie that you are not aware of things happening around 
you?" "How mentally alert do you feel at the present time?" Cronbach's a was 0.81 in the original scale and 0.86 in the present study.

\section{Problematic online gaming}

POG was measured using the Korean version of the Internet Game Addiction Questionnaire developed by the Korea Agency for Digital Opportunity and Promotion. ${ }^{20}$ The questionnaire is composed of 20 items, each of which are assessed with a four-point Likert scale. Possible scores range from 20 to 80 , where higher scores indicate a higher possibility of online gaming addiction. According to the KADOP, a total score of 38 or above indicates a high risk of online gaming addiction. Cronbach's a was 0.93 in the original scale and 0.97 in the present study.

\section{Problematic Internet use}

PIU was measured using the Internet Addiction Test (IAT).$^{21}$ IAT includes 20 items, each of which are assessed with a five-point Likert scale. Possible scores range from 20 to 100 , with scores of 70 or above classified as addictive Internet use. Cronbach's a was 0.98 in the present study.

In addition to the IAT, PIU was measured using the Korea Internet Addiction Scale (the K-scale). The K-scale is composed of 20 items, each of which are assessed with a four-point Likert scale. ${ }^{22}$ Possible scores range from 20 to 80, with higher scores indicating a higher possibility of Internet addiction. Persons with scores of 54 or above are categorized in an Internet addiction group. Cronbach's a was 0.96 in the present study.

\section{Adult attention deficit/hyperactivity disorder symptoms}

Adult ADHD symptoms were assessed using a self-report screening version of Conners' Adult ADHD Rating Scales. ${ }^{23}$ The scale consists of 30 items, each of which was assessed with a four-point Likert scale, relating to ADHD symptoms for inattention (a nine-item subscale), hyperactivity-impulsivity (also a nine-item subscale), and an ADHD index (a 12-item subscale). The ADHD index subscale was composed of the best set of items, which distinguished individuals with ADHD from those without. A T-score greater than 65 was classified as a clinical case.

\section{Childhood attention deficit/hyperactivity disorder symptoms}

Childhood ADHD symptoms were measured using the Wender Utah Rating Scale. ${ }^{24}$ The scale is a retrospective assessment tool for ADHD, and consists of 25 items, each of which are assessed with a five-point Likert scale. Possible scores range from 0 to 100, with a cutoff point of 46 meaning participant having childhood ADHD symptoms over this point.

\section{Statistical analysis}

Independent samples t-tests and Mann-Whitney $U$ tests were used to compare the characteristics of the active gamers and control groups. The Baron and Kenny ${ }^{25}$ causal steps approach was applied to test mediation. The Sobel and bootstrapping tests were conducted to assess the significance of the mediation effects. ${ }^{26-28}$ All analyses were conducted using SPSS for Windows, version 21.0 (IBM Corp., Armonk, NY, USA). Significance was set at $\mathrm{p}<0.05$.

\section{RESULTS}

All participants were of Korean ethnicity. Ages ranged from 19 to 29 years, and the mean age was 23.1 years $(\mathrm{SD}=2.4)$ (Table 1$)$. Immersive tendency scores had a wide range, from 13 to 94 , considering the possible range of 0 to 108 . The mean score was $50.0(\mathrm{SD}=17.0)$. Although the psychiatric interviews were performed to exclude participants with any major psychiatric conditions, the adult ADHD subscales identified significant problems affecting $5.9-11.8 \%$ of the participants. However, no participants scored higher than the cutoff scores on all the three adult ADHD subscales. Of the 51 participants, six (11.8\%) reported childhood ADHD symptoms, and two had no significant problems according to the current ADHD subscales. Eighteen $(35.3 \%)$ were classified as the POG group. According to the different PIU ratings, 12 (23.5\%) were classified as the PIU group, and 10 participants showed significant POG and PIU problems.

There was no significant difference in age between the active gamers, who played online games more than hours a day, and the control students (Table 2). Active gamers had higher scores in immersive tendency, ADHD symptoms, POG, and PIU than the control group.

Table 1. Sample characteristics

\begin{tabular}{llc}
\hline \multirow{2}{*}{ Variables } & \multicolumn{2}{c}{ All (N=51) } \\
\cline { 2 - 3 } & Mean \pm SD & $\mathrm{N}(\%)$ \\
\hline Age & $23.1 \pm 2.4$ & - \\
IT & $51.1 \pm 17.0$ & - \\
Inattention & $50.0 \pm 13.1$ & $6(11.8)$ \\
Hyperactivity & $42.8 \pm 10.0$ & $3(5.9)$ \\
ADHD index & $42.8 \pm 9.9$ & $3(5.9)$ \\
Childhood ADHD & $20.1 \pm 19.2$ & $6(11.8)$ \\
POG & $31.8 \pm 12.5$ & $18(35.3)$ \\
PIU (IAT) & $50.2 \pm 21.4$ & $12(23.5)$ \\
PIU (K-scale) & $42.6 \pm 13.7$ & $12(23.5)$ \\
\hline
\end{tabular}

IT: immersive tendency, POG: problematic online gaming, PIU: problematic Internet use, IAT: Internet Addiction Test, K-scale: Korea Internet Addiction Scale, ADHD: attention deficit/hyperactivity disorder 
As shown in Table 3, immersive tendency had a significant relationship with ADHD, POG, and PIU.

\section{Mediation analysis}

Immersive tendency and problematic online gaming through current attention deficit/hyperactivity disorder symptoms

To test the mediation effect of current ADHD symptoms on the association between immersive tendency and POG, a first regression was conducted on the influence of immersive tendency on POG, followed by a second regression on the influence of immersive tendency on inattention. The last regression examined inattention and POG.

Table 4 shows a significant positive relationship between immersive tendency $(\mathrm{X})$ and POG $(\mathrm{Y})(\beta=0.592, \mathrm{p}<0.001)$. Immersive tendency $(\mathrm{X})$ and inattention $(\mathrm{M})$ also had a positive relationship $(\beta=0.469, \mathrm{p}<0.001)$. Inattention $(\mathrm{M})$ was positively associated with POG $(\mathrm{Y})(\beta=0.662, \mathrm{p}<0.001)$. When inattention

Table 2. Differences between the active gamers and control groups

\begin{tabular}{|c|c|c|c|}
\hline \multirow{2}{*}{ Variables } & \multicolumn{2}{|c|}{ Active gaming (mean $\pm \mathrm{SD})$} & \multirow{2}{*}{ p-value } \\
\hline & Yes $(\mathrm{N}=23)$ & No $(\mathrm{N}=28)$ & \\
\hline Age & $22.6 \pm 2.39$ & $23.6 \pm 2.41$ & 0.050 \\
\hline IT & $61.2 \pm 15.12$ & $42.8 \pm 13.77$ & $<0.001$ \\
\hline Inattention & $58.8 \pm 13.4$ & $42.8 \pm 7.31$ & $<0.001$ \\
\hline Hyperactivity & $48.9 \pm 11.35$ & $37.8 \pm 4.86$ & $<0.001$ \\
\hline ADHD index & $50.1 \pm 9.81$ & $36.9 \pm 4.72$ & $<0.001$ \\
\hline Childhood ADHD & $31.5 \pm 21.77$ & $10.8 \pm 9.78$ & $<0.001$ \\
\hline POG & $43.2 \pm 9.82$ & $22.5 \pm 3.56$ & $<0.001$ \\
\hline PIU (IAT) & $70.9 \pm 10.75$ & $33.3 \pm 9.63$ & $<0.001$ \\
\hline PIU (K-scale) & $54.3 \pm 9.39$ & $33.0 \pm 7.87$ & $<0.001$ \\
\hline
\end{tabular}

IT: immersive tendency, POG: problematic online gaming, PIU: problematic Internet use, IAT: Internet Addiction Test, K-scale: Korea Internet Addiction Scale, ADHD: attention deficit/hyperactivity disorder
(M) was introduced into the model, the effect of immersive tendency $(\mathrm{X}$ ) on POG $(\mathrm{Y}$ ) decreased (from $\beta=0.592$, $\mathrm{p}<0.001$ to $\beta=0.282, p<0.01)$. Therefore, inattention showed a partial mediation effect on the path of immersive tendency and POG.

When hyperactivity (instead of inattention) was evaluated as a mediator, immersive tendency $(\mathrm{X})$ and hyperactivity $(\mathrm{M})$ had a positive relationship $(\beta=0.561, \mathrm{p}<0.001)$. Hyperactivity $(\mathrm{M})$ was positively associated with POG $(\mathrm{Y})(\beta=0.509, \mathrm{p}<0.001)$. When hyperactivity $(\mathrm{M})$ was introduced into the model, the effect of immersive tendency $(\mathrm{X})$ on POG $(\mathrm{Y})$ decreased (from $\beta=0.592, p<0.001$ to $\beta=0.307, p<0.05)$. Therefore, hyperactivity showed a partial mediation effect on the path of immersive tendency and POG.

When ADHD index was evaluated as a mediator, immersive tendency $(\mathrm{X})$ and $\mathrm{ADHD}$ index $(\mathrm{M})$ had a positive relationship $(\beta=0.608, p<0.001)$. ADHD index $(M)$ was positively associated with POG $(\mathrm{Y})(\beta=0.731, \mathrm{p}<0.001)$. When ADHD index $(\mathrm{M})$ was introduced into the model, the effect of immersive tendency (X) on POG (Y) decreased (from $\beta=0.592, \mathrm{p}<0.001$ to $\beta=0.148, p \geq 0.05$ ). Therefore, $A D H D$ index showed a full mediation effect on the path of immersive tendency and POG.

Based on the $\mathrm{R}^{2}$ values, the mediation model of POG, with inattention, explained $69.2 \%$ of the variance in POG, the highest of the three models.

Figure 1 displays the results. Both the Sobel and bootstrap tests confirmed that the indirect effect of $\mathrm{X}$ on $\mathrm{Y}$ via $\mathrm{M}$ was significant in all the mediator models $(\mathrm{z}=3.432, \mathrm{p}<0.001$ in the inattention model; $\mathrm{z}=3.824, \mathrm{p}<0.001$ in the hyperactivity model; and $\mathrm{z}=4.744, \mathrm{p}<0.001$ in the ADHD index model).

Effect of immersive tendency on problematic Internet use via current attention deficit/hyperactivity disorder symptoms

To test the mediation effect of current ADHD symptoms on the association between immersive tendency and PIU, the first regression concerned the influence of immersive tendency on PIU, while the second regression concerned the in-

Table 3. Pearson's correlation analysis of immersive tendency, ADHD symptoms, POG, and PIU

\begin{tabular}{|c|c|c|c|c|c|c|c|}
\hline & 1 & 2 & 3 & 4 & 5 & 6 & 7 \\
\hline 1. IT & 1 & & & & & & \\
\hline 2. Inattention & 0.47 & 1 & & & & & \\
\hline 3. Hyperactivity & 0.56 & 0.72 & 1 & & & & \\
\hline 4. ADHD index & 0.61 & 0.91 & 0.82 & 1 & & & \\
\hline 5. Childhood ADHD & 0.63 & 0.62 & 0.61 & 0.70 & 1 & & \\
\hline 6. POG & 0.59 & 0.79 & 0.68 & 0.82 & 0.71 & 1 & \\
\hline 7. PIU (IAT) & 0.63 & 0.78 & 0.63 & 0.76 & 0.68 & 0.92 & 1 \\
\hline 8. PIU (K-scale) & 0.66 & 0.79 & 0.71 & 0.80 & 0.65 & 0.89 & 0.92 \\
\hline
\end{tabular}

All pearson's $r$ are significant $(\mathrm{p}<0.001)$. IT: immersive tendency, POG: problematic online gaming, PIU: problematic Internet use, IAT: Internet Addiction Test, K-scale: Korea Internet Addiction Scale, ADHD: attention deficit/hyperactivity disorder 
Table 4. Mediator analyses of immersive tendency, ADHD symptoms, and POG

\begin{tabular}{|c|c|c|c|c|c|}
\hline Mediator & Detecting steps in mediation model & B & SE B & $\beta$ & $\mathrm{R}^{2}$ \\
\hline \multirow[t]{10}{*}{ Inattention } & Step 1 (path c) & & & & \\
\hline & Outcome: POG & & & & \\
\hline & Predictor: IT & 0.437 & 0.085 & $0.592^{* * *}$ & 0.351 \\
\hline & Step 2 (path a) & & & & \\
\hline & Outcome: Inattention & & & & \\
\hline & Predictor: IT & 0.363 & 0.098 & $0.469^{* * *}$ & 0.220 \\
\hline & Step 3 (paths b and c') & & & & \\
\hline & Outcome: POG & & & & \\
\hline & Mediator: Inattention (path b) & 0.631 & 0.086 & $0.662^{* * *}$ & \\
\hline & Predictor: IT (path c') & 0.208 & 0.067 & $0.282^{* *}$ & 0.692 \\
\hline \multirow[t]{7}{*}{ Hyperactivity } & Step 2 (path a) & & & & \\
\hline & Outcome: Hyperactivity & & & & \\
\hline & Predictor: IT & 0.331 & 0.070 & $0.561^{* * *}$ & 0.315 \\
\hline & Step 3 (paths b and c') & & & & \\
\hline & Outcome: POG & & & & \\
\hline & Mediator: Hyperactivity (path b) & 0.636 & 0.150 & $0.509^{* * *}$ & \\
\hline & Predictor: IT (path c') & 0.226 & 0.088 & $0.307^{*}$ & 0.528 \\
\hline \multirow[t]{7}{*}{ ADHD index } & Step 2 (path a) & & & & \\
\hline & Outcome: ADHD index & & & & \\
\hline & Predictor: IT & 0.355 & 0.066 & $0.608^{* * *}$ & 0.369 \\
\hline & Step 3 (paths b and c') & & & & \\
\hline & Outcome: POG & & & & \\
\hline & Mediator: ADHD index (path b) & 0.923 & 0.128 & $0.731^{* * *}$ & \\
\hline & Predictor: IT (path c') & 0.109 & 0.075 & 0.148 & 0.688 \\
\hline
\end{tabular}

${ }^{*} \mathrm{p}<0.05,{ }^{* *} \mathrm{p}<0.01,{ }^{* * *} \mathrm{p}<0.001$. IT: immersive tendency, POG: problematic online gaming, ADHD: attention deficit/hyperactivity disorder

fluence of immersive tendency on inattention. The last regression examined inattention and PIU.

Table 5 shows a significant positive relationship between immersive tendency (X) and PIU (Y) $(\beta=0.629, \mathrm{p}<0.001)$. Immersive tendency $(\mathrm{X})$ and inattention $(\mathrm{M})$ had a positive relationship ( $\beta=0.469, \mathrm{p}<0.001)$. Inattention $(\mathrm{M})$ was positively associated with PIU $(\mathrm{Y})(\beta=0.618, \mathrm{p}<0.001)$. When inattention $(\mathrm{M})$ was introduced into the model, the effect of immersive tendency (X) on PIU (Y) decreased (from $\beta=0.629, \mathrm{p}<0.001$ to $\beta=0.339, p<0.001)$. Therefore, inattention showed a partial mediation effect on the path of immersive tendency and PIU.

When hyperactivity (instead of inattention) was evaluated as a mediator, immersive tendency $(\mathrm{X})$ and hyperactivity $(\mathrm{M})$ had a positive relationship $(\beta=0.561, \mathrm{p}<0.001)$. Hyperactivity (M) was positively associated with PIU (Y) $(\beta=0.409, \mathrm{p}<0.01)$. When hyperactivity $(\mathrm{M})$ was introduced into the model, the effect of immersive tendency (X) on PIU (Y) decreased (from $\beta=0.629, p<0.001$ to $\beta=0.400, p<0.01)$. Therefore, hyperactivity showed a partial mediation effect on the path of immersive tendency and PIU.

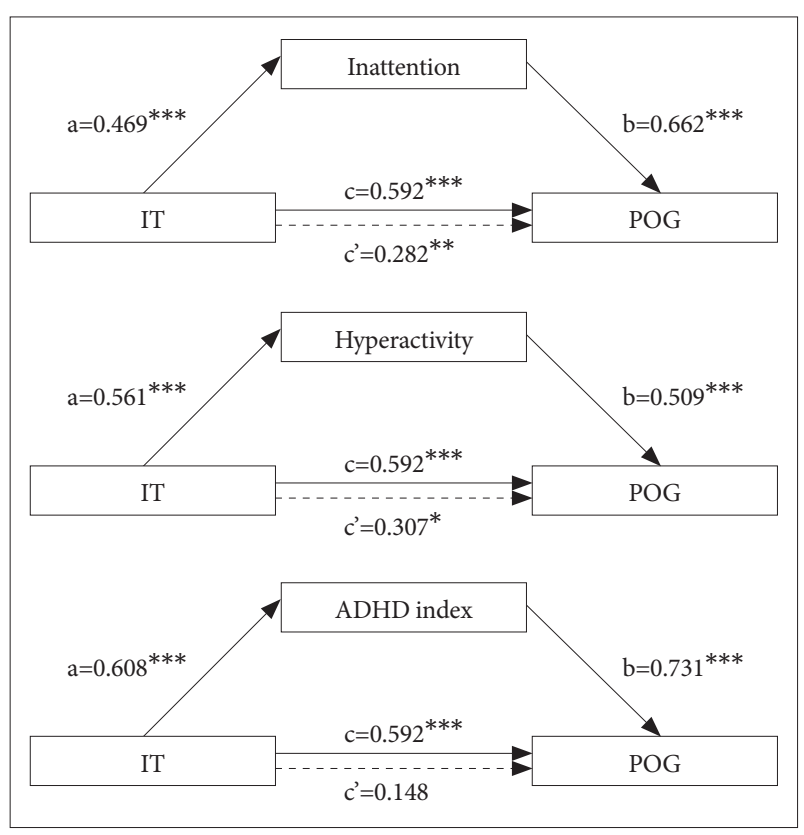

Figure 1. Mediation model of IT, attention deficit/hyperactivity symptoms, and POG. IT: immersive tendency, POG: problematic online gaming, ADHD: attention deficit/hyperactivity disorder. ${ }^{*} \mathrm{p}<0.05$, ${ }^{* *} p<0.01,{ }^{* * *} p<0.001$. 
Table 5. Mediator analyses of immersive tendency, ADHD symptoms, and PIU

\begin{tabular}{|c|c|c|c|c|c|}
\hline Mediator & Detecting steps in mediation model & $\mathrm{B}$ & SE B & $\beta$ & $\mathrm{R}^{2}$ \\
\hline \multirow[t]{10}{*}{ Inattention } & Step 1 (path c) & & & & \\
\hline & Outcome: PIU (IAT) & & & & \\
\hline & Predictor: IT & 0.792 & 0.140 & $0.629^{* * *}$ & 0.396 \\
\hline & Step 2 (path a) & & & & \\
\hline & Outcome: Inattention & & & & \\
\hline & Predictor: IT & 0.363 & 0.098 & $0.469^{* * *}$ & 0.220 \\
\hline & Step 3 (paths b and c') & & & & \\
\hline & Outcome: PIU (IAT) & & & & \\
\hline & Mediator: Inattention (path b) & 1.005 & 0.147 & $0.618^{* * *}$ & \\
\hline & Predictor: IT (path c') & 0.427 & 0.114 & $0.339^{* * *}$ & 0.693 \\
\hline \multirow[t]{7}{*}{ Hyperactivity } & Step 2 (path a) & & & & \\
\hline & Outcome: Hyperactivity & & & & \\
\hline & Predictor: IT & 0.331 & 0.070 & $0.561^{* * *}$ & 0.315 \\
\hline & Step 3 (paths b and c') & & & & \\
\hline & Outcome: PIU (IAT) & & & & \\
\hline & Mediator: Hyperactivity (path b) & 0.873 & 0.261 & $0.409^{* *}$ & \\
\hline & Predictor: IT (path c') & 0.503 & 0.154 & $0.400^{* *}$ & 0.510 \\
\hline \multirow[t]{7}{*}{ ADHD index } & Step 2 (path a) & & & & \\
\hline & Outcome: ADHD index & & & & \\
\hline & Predictor: IT & 0.355 & 0.066 & $0.608^{* * *}$ & 0.369 \\
\hline & Step 3 (paths b and c') & & & & \\
\hline & Outcome: PIU (IAT) & & & & \\
\hline & Mediator: ADHD index (path b) & 1.307 & 0.239 & $0.606^{* * *}$ & \\
\hline & Predictor: IT (path c') & 0.329 & 0.140 & $0.261^{*}$ & 0.627 \\
\hline
\end{tabular}

${ }^{*} \mathrm{p}<0.05,{ }^{* *} \mathrm{p}<0.01,{ }^{* * *} \mathrm{p}<0.001$. IT: immersive tendency, PIU: problematic Internet use, IAT: Internet Addiction Test, ADHD: attention deficit/hyperactivity disorder

When $\mathrm{ADHD}$ index was evaluated as a mediator, immersive tendency $(\mathrm{X})$ and $\mathrm{ADHD}$ index $(\mathrm{M})$ had a positive relationship $(\beta=0.608, p<0.001)$. ADHD index $(M)$ was positively associated with PIU (Y) $(\beta=0.606, \mathrm{p}<0.001)$. When ADHD index $(\mathrm{M})$ was introduced into the model, the effect of immersive tendency (X) on PIU (Y) decreased (from $\beta=0.629$, $\mathrm{p}<0.001$ to $\beta=0.261, \mathrm{p}<0.05)$. Therefore, ADHD index showed a partial mediation effect on the path of immersive tendency and PIU.

Based on the $\mathrm{R}^{2}$ values, the mediation model of PIU, with inattention, explained $69.3 \%$ of the variance in PIU, the highest of the three models.

Figure 2 displays the results. Both the Sobel and bootstrap tests confirmed that the indirect effect of $\mathrm{X}$ on $\mathrm{Y}$ via $\mathrm{M}$ was significant in all the mediator models $(z=3.405, p<0.001$ in the inattention model; $\mathrm{z}=3.646, \mathrm{p}<0.001$ in the hyperactivity model; and $\mathrm{z}=4.511, \mathrm{p}<0.001$ in the ADHD index model).

Moreover, when PIU was evaluated with the K-scale instead of the IAT, all three adult ADHD subscales showed a partial mediation effect on the path of immersive tendency and PIU, with the inattention model explaining the variance best (Supplementary Table 1 in the online-only Data Supplement).

\section{Childhood ADHD symptoms}

To compare the mediation effect of childhood ADHD symptoms on current $\mathrm{ADHD}$ symptoms, the mediation analyses were conducted with scores from the Wender Utah Rating Scale. Childhood ADHD symptoms demonstrated a full mediation effect on the path of immersive tendency and POG (Table 6). On the path of immersive tendency and PIU, childhood ADHD symptoms showed a partial mediation effect. Based on the $\mathrm{R}^{2}$ values, the mediation model with childhood ADHD symptoms explained $53.7 \%$ of the variance in POG and $52.1 \%$ of the variance in PIU, which was much lower than the models with current ADHD symptoms and inattention (69.2\% in POG; 69.3\% in PIU). 


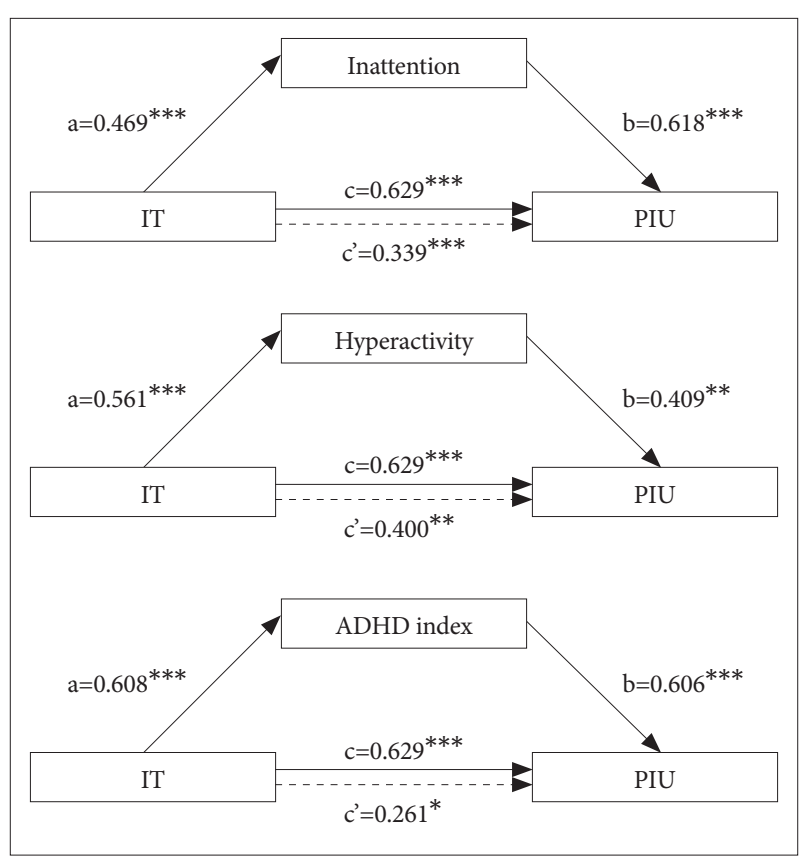

Figure 2. Mediation model of IT, ADHD symptom, and PIU. IT: immersive tendency, PIU: problematic Internet use, ADHD: attention deficit/hyperactivity disorder. ${ }^{*} p<0.05,{ }^{* *} p<0.01,{ }^{* * *} p<0.001$.

\section{DISCUSSION}

The current study presents, to the best of our knowledge, the first report demonstrating that the association between immersive tendency and POG/PIU is mediated by ADHD symptoms. Although the association between ADHD and POG/PIU has been investigated, there are few studies on the effect of immersive tendency symptoms, and no studies have observed immersive tendency and ADHD simultaneously. This study found that current $\mathrm{ADHD}$ symptoms, especially inattention, mediate the effect of immersive tendency on POG/PIU, which explains the mediation model better than ADHD symptoms during childhood.

Within online gaming, the motivations of players differ from one another and depend on personal factors. ${ }^{29}$ In a study with massively multi-player online gamers, those who play for immersion motivation showed association with PIU. ${ }^{30}$ The immersion motivation consists of discovery, role-playing, customization and escapism.

In a recent study on differences between addicted gamers and engaged players, the immersion motivation showed significant group difference. ${ }^{31}$ However, the immersion motivation in those studies was evaluated on gaming experiences. Therefore, motivation could not be evaluated before game exposure. On the contrary, the immersive tendency questionnaire measures differences in personal tendencies toward presence through engagement in everyday activities, such as watching movies and television programs, reading books, and dreaming. ${ }^{19}$ In a previous study on the differences between gaming addiction and high gaming engagement, addicted gamers scored higher on the immersive tendency questionnaire than highly engaged gamers. ${ }^{15}$ However, the study did not evaluate other comorbid conditions, such as depression and anxiety. In the present study, the psychiatrist interviews and depression ratings excluded participants with comorbid conditions. Therefore, the study can more clearly explain the role of immersive tendency as a specific risk factor for POG/ PIU. Moreover, gamers who score high on immersive tendency are absorbed and immersed in computer games through not only spatial presence, but also "flow," the sensation of being involved in gaming action. ${ }^{32}$ Through these processes, a person with higher immersive tendency can experience the more hedonic effect of Internet gaming.

According to genetic evidence and stimulant-response studies, ADHD is a subtype of reward deficiency syndrome with dysfunction in the brain reward cascade such as in the dopamine system. ${ }^{33}$ From childhood to adulthood, ADHD is associated with both the initiation and persistence of habit-forming illnesses, such as alcohol dependence and substance addiction. ${ }^{34}$ Moreover, the association between ADHD and addiction is not limited to substances. Sustained ADHD throughout childhood and young adulthood increases the severity of gambling problems. ${ }^{35}$ The relationship between $\mathrm{ADHD}$ and gaming addiction has emerged from evidence on comorbidity, common mechanisms, and genetic associations. ${ }^{10}$ Patients with ADHD play an internet game, which releases dopamine, for self-medication like other addictive substances. ${ }^{36}$ A person with higher immersive tendency may have a more exaggerated dopamine release in a virtual gaming environment, which makes internet gaming more addictive. Patients with higher immersive tendency might be more susceptible to internet gaming, and this susceptibility may be mediated by ADHD.

In addition, a previous study recorded that excessive online gamers experience biological changes in the ECG and respiratory systems, compared to a control group with similar demographic conditions. ${ }^{17}$ The findings from this study revealed a conditional subordinate relationship between central inhibitory and autonomic responses, which result in excessive gaming when experiencing pleasurable online stimuli. Additional methods could be conducted spontaneously to provide a more solid background to the findings from present study.

The present study has several limitations. First, the small number of participants in a highly homogenous social group, active gamers, may not sufficient to generalize the findings. To minimize possible confounding effects, we applied tightly controlled conditions. Although most studies have focused on children and adolescents, the prevalence of problematic gam- 
Table 6. Mediator analysis of immersive tendency, childhood ADHD, POG, and PIU

\begin{tabular}{|c|c|c|c|c|c|}
\hline Outcome & Detecting steps in mediation model & B & SE B & $\beta$ & $\mathrm{R}^{2}$ \\
\hline \multirow[t]{10}{*}{ POG } & Step 1 (path c) & & & & \\
\hline & Outcome: POG & & & & \\
\hline & Predictor: IT & 0.437 & 0.085 & $0.592^{* * *}$ & 0.351 \\
\hline & Step 2 (path a) & & & & \\
\hline & Outcome: childhood ADHD & & & & \\
\hline & Predictor: IT & 0.715 & 0.125 & $0.633^{* * *}$ & 0.401 \\
\hline & Step 3 (paths b and c') & & & & \\
\hline & Outcome: POG & & & & \\
\hline & Mediator: childhood ADHD (path b) & 0.363 & 0.083 & $0.557^{* * *}$ & \\
\hline & Predictor: IT (path c') & 0.177 & 0.094 & 0.24 & 0.537 \\
\hline \multirow[t]{10}{*}{ PIU (IAT) } & Step 1 (path c) & & & & \\
\hline & Outcome: POG & & & & \\
\hline & Predictor: IT & 0.531 & 0.087 & $0.659^{* * *}$ & 0.434 \\
\hline & Step 2 (path a) & & & & \\
\hline & Outcome: childhood ADHD & & & & \\
\hline & Predictor: IT & 0.715 & 0.125 & $0.633^{* * *}$ & 0.401 \\
\hline & Step 3 (paths b and c') & & & & \\
\hline & Outcome: POG & & & & \\
\hline & Mediator: childhood ADHD (path b) & 0.271 & 0.092 & $0.380^{* *}$ & \\
\hline & Predictor: IT (path c') & 0.337 & 0.104 & $0.418^{* *}$ & 0.521 \\
\hline
\end{tabular}

${ }^{* *} \mathrm{p}<0.01,{ }^{* * *} \mathrm{p}<0.001$. IT: immersive tendency, POG: problematic online gaming, PIU: problematic Internet use, IAT: Internet Addiction Test, ADHD: attention deficit/hyperactivity disorder

ing is also high in young adults, especially males. ${ }^{37}$ To generalize the results of the present study, further studies that recruit a larger number of participants to cross-check the relationship between diverse demographic factors such as age, gender, education level are required.

Second, the present study did not investigate other comorbid psychopathologies, such as depression and anxiety. Immersive tendency may be a common risk factor for IGD, and depression can mediate the effect of the immersive tendency on IGD. A third limitation of the present study is that at the time of writing, there is no standard assessment instrument for IGD. Three POG/PIU scales were used to address this problem.

We observed the mediating effect of ADHD on the association between immersive tendency and IGD. It has been documented that ADHD symptoms must be controlled to treat IGD. We cautiously suggest that immersive tendency be evaluated as a factor that increases individual susceptibility to IGD.

\section{Supplementary Materials}

The online-only Data Supplement is available with this article at https://doi.org/10.30773/pi.2019.0173.

\section{Acknowledgments}

This work was supported by grants from National Research Foundation of Korea (NRF-2010-0010632) and 'Platform development for stress management and analysis of risk factors' Research Fund (Project Number 1.160108.01) of UNIST (Ulsan National Institute of Science \& Technology)'.

\section{Conflicts of Interest}

The authors have no potential conflicts of interest to disclose.

\section{Author Contributions}

Conceptualization: Dooyoung Jung, Seong-hoon Jeong, Yeni Kim, Yong Min Ahn, Bong-jin Hahm. Data curation: Dooyoung Jung, Eun-jung Shim. Formal analysis: Dooyoung Jung, Eun-jung Shim. Funding acquisition: Seong Hoon Jeong, Yeni Kim, Yong Min Ahn, Bong-jin Hahm. Investigation: Eun-young Kim, Jae Seung Chang. Methodology: Eun-young Kim, Jae Seung Chang, Seong-hoon Jeong. Project administration: Yong Min Ahn, Bong-jin Hahm. Resources: Bong-jin Hahm. Software: Seong-hoon Jeong. Supervision: Bong-jin Hahm. Validation: Eun-jung Shim, Kwanglo Lee. Visualization: Eun-jung Shim, Hyeonggyu Park, Sangil Lee. Writingoriginal draft: Dooyoung Jung. Writing-review \& editing: Dooyoung Jung, Hyeonggyu Park, Kwanglo Lee, Sangil Lee.

\section{ORCID iDs}

Dooyoung Jung Eun-jung Shim Hyeonggyu Park Kwanglo Lee Sangil Lee Eun-young Kim Jae Seung Chang Seong-hoon Jeong https://orcid org/0000-0002-7404-9056 
Yeni Kim

Yong Min Ahn

https://orcid.org/0000-0002-2624-8026

Bong-jin Hahm

https://orcid.org/0000-0002-4458-797X

https://orcid.org/0000-0002-2366-3275

\section{REFERENCES}

1. American Psychiatric Association. Diagnostic and Statistical Manual of Mental Disorders (5th Ed.). Arlington, VA: American Psychiatric Publishing; 2013.

2. Petry NM, Rehbein F, Gentile DA, Lemmens JS, Rumpf HJ, Mossle T, et al. An international consensus for assessing internet gaming disorder using the new DSM-5 approach. Addiction 2014;109:1399-1406.

3. Starcevic V. Is Internet addiction a useful concept? Aust N Z J Psychiatry 2013;47:16-19.

4. Griffiths MD, Davies MN, Chappell D. Demographic factors and playing variables in online computer gaming. Cyberpsychol Behav 2004;7: 479-487.

5. Sasmaz T, Oner S, Kurt AO, Yapici G, Yazici AE, Bugdayci R, et al. Prevalence and risk factors of Internet addiction in high school students. Eur J Public Health 2014;24:15-20.

6. Park MH, Park EJ, Choi J, Chai S, Lee JH, Lee C, et al. Preliminary study of Internet addiction and cognitive function in adolescents based on IQ tests. Psychiatry Res 2011;190:275-281.

7. Zhou Z, Yuan G, Yao J. Cognitive biases toward Internet game-related pictures and executive deficits in individuals with an internet game addiction. PLoS One 2012;7:e48961.

8. Ko CH, Yen JY, Chen CC, Chen SH, Yen CF. Gender differences and related factors affecting online gaming addiction among Taiwanese adolescents. J Nerv Ment Dis 2005;193:273-277.

9. Hyun GJ, Han DH, Lee YS, Kang KD, Yoo SK, Chung US, et al. Risk factors associated with online game addiction: A hierarchical model. Comput Hum Behav 2015;48:706-713.

10. Weinstein A, Weizman A. Emerging association between addictive gaming and attention-deficit/hyperactivity disorder. Curr Psychiatry Rep 2012;14:590-597.

11. Ko CH, Yen JY, Chen CS, Chen CC, Yen CF. Psychiatric comorbidity of internet addiction in college students: an interview study. CNS Spectr 2008;13:147-153.

12. Carli V, Durkee T, Wasserman D, Hadlaczky G, Despalins R, Kramarz E, et al. The association between pathological internet use and comorbid psychopathology: a systematic review. Psychopathology 2013;46:1-13.

13. Strittmatter E, Kaess M, Parzer P, Fischer G, Carli V, Hoven CW, et al. Pathological Internet use among adolescents: Comparing gamers and non-gamers. Psychiatry Res 2015;228:128-135.

14. Hsu SH, Wen MH, Wu MC. Exploring user experiences as predictors of MMORPG addiction. Comput Educ 2009;53:990-999.

15. Lehenbauer-Baum M, Fohringer M. Towards classification criteria for internet gaming disorder: Debunking differences between addiction and high engagement in a German sample of World of Warcraft players. Comput Hum Behav 2015;45:345-351.

16. Young KS, Rodgers RC. The relationship between depression and Internet addiction. Cyberpsychol Behav 1998;1:25-28.

17. Chang JS, Kim EY, Jung D, Jeong SH, Kim Y, Roh MS, et al. Altered cardiorespiratory coupling in young male adults with excessive online gaming. Biol Psychol 2015;110:159-166.
18. Montgomery SA, Asberg M. A new depression scale designed to be sensitive to change. Br J Psychiatry 1979;134:382-389.

19. Witmer BG, Singer MJ. Measuring presence in virtual environments: a presence questionnaire. Presence Teleop Virt 1998;7:225-240.

20. Promotion KAfDO. A Study of the Development of Internet Game Addiction Scale for Children and Adolescents. Seoul: KADO; 2006.

21. Young KS. Caught in the Net: How to Recognize the Signs of Internet Addiction-And a Winning Strategy for Recovery. New York, NY: JohnWiley \& Sons; 1998.

22. Kim D. The Follow Up Study of Internet Addiction Proneness Scale. Seoul: Korea Agency for Digital Opportunity and Promotion; 2008.

23. Conners CK, Erhardt D, Sparrow EP. Conners' Adult ADHD Rating Scales: Technical Manual. New York, NY: Multi-Health Systems; 1999.

24. Ward MF, Wender PH, Reimherr FW. The Wender Utah Rating Scale: an aid in the retrospective diagnosis of childhood attention deficit hyperactivity disorder. Am J Psychiatry 1993;150:885-890.

25. Baron RM, Kenny DA. The moderator-mediator variable distinction in social psychological research: conceptual, strategic, and statistical considerations. J Pers Soc Psychol 1986;51:1173-1182.

26. Sobel ME. Asymptotic confidence intervals for indirect effects in structural equation models. Sociol Methodol 1982;13:290-312.

27. Preacher KJ, Hayes AF. SPSS and SAS procedures for estimating indirect effects in simple mediation models. Behav Res Methods Instrum Comput 2004;36:717-731.

28. Mackinnon DP, Lockwood CM, Williams J. Confidence limits for the indirect effect: distribution of the product and resampling methods. Multivariate Behav Res 2004;39:99-128.

29. Yee N. Motivations for play in online games. Cyberpsychol Behav 2006;9:772-775.

30. Caplan S, Williams D, Yee N. Problematic Internet use and psychosocial well-being among MMO players. Comput Hum Behav 2009;25: 1312-1319.

31. Lehenbauer-Baum M, Klaps A, Kovacovsky Z, Witzmann K, Zahlbruckner R, Stetina BU. Addiction and engagement: an explorative study toward classification criteria for internet gaming disorder. Cyberpsychol Behav Soc Netw 2015;18:343-349.

32. Weibel D, Wissmath B. Immersion in computer games: the role of spatial presence and flow. Int J Comput Games Technol 2011;1-14.

33. Blum K, Chen AL, Braverman ER, Comings DE, Chen TJ, Arcuri V, et al. Attention-deficit-hyperactivity disorder and reward deficiency syndrome. Neuropsychiatr Dis Treat 2008;4:893-918.

34. Ohlmeier MD, Peters K, Te Wildt BT, Zedler M, Ziegenbein M, Wiese $\mathrm{B}$, et al. Comorbidity of alcohol and substance dependence with attention-deficit/hyperactivity disorder (ADHD). Alcohol Alcohol 2008; 43:300-304.

35. Breyer JL, Botzet AM, Winters KC, Stinchfield RD, August G, Realmuto G. Young adult gambling behaviors and their relationship with the persistence of ADHD. J Gambl Stud 2009;25:227-238.

36. Han DH, Lee YS, Na C, Ahn JY, Chung US, Daniels MA, et al. The effect of methylphenidate on Internet video game play in children with attention-deficit/hyperactivity disorder. Compr Psychiatry 2009;50:251-256.

37. Haagsma MC, Pieterse ME, Peters O. The prevalence of problematic video gamers in the Netherlands. Cyberpsychol Behav Soc Netw 2012; 15:162-168. 
Supplementary Table 1. Mediator analyses of immersive tendency, ADHD symptom and problematic internet use assessed using the Korea Internet Addiction Scale

\begin{tabular}{|c|c|c|c|c|c|}
\hline Mediator & Detecting steps in mediation model & B & SE B & B & $\mathrm{R}^{2}$ \\
\hline \multirow[t]{10}{*}{ Inattention } & Step 1 (path c) & & & & \\
\hline & Outcome: PIU (K-scale) & & & & \\
\hline & Predictor: IT & 0.531 & 0.087 & $0.659^{* * *}$ & 0.434 \\
\hline & Step 2 (path a) & & & & \\
\hline & Outcome: Inattention & & & & \\
\hline & Predictor: IT & 0.363 & 0.098 & $0.469^{* * *}$ & 0.220 \\
\hline & Step 3 (paths b and c') & & & & \\
\hline & Outcome: PIU (K-scale) & & & & \\
\hline & Mediator: Inattention (path b) & 0.635 & 0.089 & $0.610^{* * *}$ & \\
\hline & Predictor: IT (path c') & 0.300 & 0.069 & $0.373^{* * *}$ & 0.725 \\
\hline \multirow[t]{7}{*}{ Hyperactivity } & Step 2 (path a) & & & & \\
\hline & Outcome: Hyperactivity & & & & \\
\hline & Predictor: IT & 0.331 & 0.070 & $0.561^{* * *}$ & 0.315 \\
\hline & Step 3 (paths b and c') & & & & \\
\hline & Outcome: PIU (K-scale) & & & & \\
\hline & Mediator: Hyperactivity (path b) & 0.677 & 0.150 & $0.496^{* * *}$ & \\
\hline & Predictor: IT (path c') & 0.307 & 0.089 & $0.381^{* *}$ & 0.603 \\
\hline \multirow[t]{7}{*}{ ADHD index } & Step 2 (path a) & & & & \\
\hline & Outcome: ADHD index & & & & \\
\hline & Predictor: IT & 0.355 & 0.066 & $0.608^{* * *}$ & 0.369 \\
\hline & Step 3 (paths b and c') & & & & \\
\hline & Outcome: PIU (K-scale) & & & & \\
\hline & Mediator: ADHD index (path b) & 0.866 & 0.141 & $0.627^{* * *}$ & \\
\hline & Predictor: IT (path c') & 0.224 & 0.082 & $0.278^{* *}$ & 0.683 \\
\hline
\end{tabular}

Both the Sobel and bootstrap tests confirmed that the indirect effect of $\mathrm{X}$ on $\mathrm{Y}$, via $\mathrm{M}$, was significant in all the mediator models $(\mathrm{z}=3.418$, $\mathrm{p}<0.001$ in the inattention model; $\mathrm{z}=3.934, \mathrm{p}<0.001$ in the hyperactivity model; and $\mathrm{z}=4.647, \mathrm{p}<0.001$ in the ADHD index model). ${ }^{* *} \mathrm{p}<0.01$, ${ }_{* * *} \mathrm{p}<0.001$. IT: immersive tendency, PIU: problematic Internet use, K-scale: Korea Internet Addiction Scale, ADHD: attention deficit/hyperactivity disorder 